\title{
Management of Pancreatic Injuries with Blunt Abdominal Trauma in Children, Case Series
}

\author{
Asem Ghasoup*, Omar Sadieh, Ahmad Mansor, Qais Alani and Jamil Sawaqed
}

Al Bashir Hospital, Ministry of Health, Amman, Jordan

\begin{abstract}
Objectives: Trauma is the leading cause of death in children. Abdominal trauma with Injuries to the liver, spleen and kidneys are common in children and many of these injuries nowadays are treated non-operatively, where as Pancreatic injuries are uncommon and its management still controversial. The aim of this study is to report the outcome of management in a series of children with pancreatic injury.

Methods: Ten Children less than 10 years of age treated at our institution with pancreatic injury between the period of May 2000 and May 2010 and reviewed retrospectively. 8 cases admitted from the emergency room and two cases referred from another facility. Diagnosis made on clinical suspicion, biochemistry tests and radiological confirmation (ultrasound and CT scan). Management was started according to the grade of Injury.

Results: Seven boys and three girls aged between 2.5 and 10 years sustained pancreatic injuries: three cases had grade I Pancreatic injury (minor contusion), three cases with grade II (major contusion without duct injury or tissue loss), two with grade III (distal transection and duct injury), one case with grade IV (proximal transection) and one case with pancreatic transaction and extensive duodenal injury (grade IV with associated injury). Grade I and II injuries were successfully managed without surgery. Children with grade III injuries were treated conservatively, but each developed a symptomatic pseudo cyst that failed to resolve with percutaneous drainage and underwent spleen-sparing distal pancreatectomy. The child with grade IV transected pancreatic neck was treated by Roux-en-Y jejunostomy drainage and the last case with the Grade IV and associated duodenal injury treated with Whipple procedure. Amylase level was normal in Grade I and II injuries and increased as the grade of injury is higher. Al children made a full recovery. Median follow up was 45 days.

Conclusion: Pancreatic injuries in children are uncommon and its management still controversial, some Institutions prefers conservative management, whereas others hold on the surgical option. Level of amylase is correlated with the severity of the injury when pancreatic injury is diagnosed. The management of pancreatic injuries in children depends on the grade of injury, presence of associated injuries and Hospital expertise.
\end{abstract}

Keywords: Pancreatic injury; Children; Blunt abdominal trauma

\section{Introduction}

Trauma is the leading cause of death in children above the age of one [1]. Injuries to the liver, spleen and kidneys are common squeal of abdominal trauma in children and many of these injuries are nowadays treated non-operatively [2]. Pancreatic injuries in children are uncommon and rarely described if compared to adults which are documented in literatures [3,4]. Non-surgical management of minor pancreatic injury in children is well accepted; however the management of serious pancreatic injury remains controversial. Pancreatic injuries often results in severe complications, Some institutions recommend an aggressive surgical approach to reduce the incidence of morbidity and prolonged hospitalization, others advocate non-surgical management of pancreatic injury in children would lead to a good clinical outcome [5].

The aim of our study, therefore, is to assess the management and outcome of pancreatic trauma in children age less than 10 years and treated at our institution.

\section{Methods}

All children were less than 10 years of age, and presented or referred with pancreatic injury to our institution (Al Bashir Teaching Hospital-Amman-Jordan) between the period of May 2000 and May 2010. A retrospective case note review was carried out, Data extracted include; mode and time of presentation, mechanism of injury, clinical features, investigations on admission, transfer from another facility,
Inpatient management and follow up. Pancreatic injury was graded according to the classification of the Organ Injury Scaling Committee of the American Association for the Surgery of Trauma (OIS-AAST) as shown on (Table 1) [6].

\section{Results}

Ten children identified with pancreatic injury after a blunt abdominal trauma over a period of 10 -years. Seven were boys (70\%) and three were girls (30\%). Median age at presentation was 5 years (range between 2.5-10 years). Eight children presented to our institution, and two cases transferred from another facility. The median time of transfer was 72 hours (range from 2 hours-one week). The median number of children admitted with a pancreatic injury was one per annum.

The commonest mechanism of injury was a localized impact to the epigastrium, with compression of pancreas against the vertebral

*Corresponding author: Asem Ghasoup, Al Bashir Hospital, Ministry of Health Amman, Jordan, E-mail: black_silence_2000@yahoo.com

Received February 12, 2013; Accepted March 15, 2013; Published March 18, 2013

Citation: Ghasoup A, Sadieh O, Mansor A, Alani Q, Sawaqed J (2013) Management of Pancreatic Injuries with Blunt Abdominal Trauma in Children, Case Series. J Trauma Treat 2: 160. doi:10.4172/2167-1222.1000160

Copyright: (c) 2013 Ghasoup A, et al. This is an open-access article distributed under the terms of the Creative Commons Attribution License, which permits unrestricted use, distribution, and reproduction in any medium, provided the original author and source are credited. 


\begin{tabular}{|c|c|l|}
\hline Grade & Injury & Description \\
\hline \multirow{2}{*}{ I } & Hematoma & Minor contusion without duct injury \\
\cline { 2 - 3 } & Laceration & Superficial laceration without the duct injury \\
\hline \multirow{2}{*}{ II } & Hematoma & Major contusion without duct injury or tissue loss \\
\cline { 2 - 3 } & Laceration & Major laceration without the duct injury or tissue loss \\
\hline III & Laceration & Distal transaction or parenchymal injury with duct injury \\
\hline \multirow{2}{*}{ IV } & Laceration & $\begin{array}{l}\text { Proximal (to right of superior mesenteric vein) transaction } \\
\text { or parenchymal injury }\end{array}$ \\
\hline V & Laceration & Massive disruption of pancreatic head \\
\hline
\end{tabular}

Table 1: American Association of the Surgery of Trauma (AAST) classification of pancreatic injury [6].

column. In our series, these injuries were caused by impact of the end of the handlebars of a bicycle ( $70 \%$ of cases), a deceleration injury when the pancreas stretched over the vertebral column and seen in falls from a height over the back of the child (20\% of cases). In one case, the injury was due to a trauma with a hard object hit directly the epigastrium. Investigations carried out to all the patients on admission, including complete blood count, electrolytes, glucose, liver and kidney function test and blood gas analysis.

The suspicion of pancreatic injury was raised by elevated serum amylase levels in four cases (40\%), the diagnosis for the rest of cases (60\%) made by clinical suspicion and confirmed by Ultrasound (US) scanning and/or Computerized Tomography (CT) scanning. The Initial management includes a 'nil by mouth' regimen, intravenous fluids and analgesia, and admission either to intermediate or intensive care unit according to the severity of the injury and the hemodynamic stability of the patient.

Associated injuries were found in 3 children (30\%). Two cases with liver tears and one with a splenic tear, fracture to the sixth thoracic vertebra and duodenal injury. Three patients (30\%) classified with grade I (minor contusion) (Figure 1), and three patients (30\%) with grade II (major contusion without duct injury or tissue loss) (Figure 2). All six cases were managed conservatively. Two patients (20\%) with grade III (distal transection and duct injury) (Figure 3 ) had persistently high serum amylase levels and underwent Diagnostic endoscopic retrograde cholangiopancreatography (ERCP) which demonstrated an obstruction to flow of contrast in the main pancreatic duct at the junction of the proximal one-third and distal two-thirds, those patients developed a symptomatic pseudo cyst that failed to resolve with percutaneous drainage and underwent a spleen-sparing distal pancreatectomy.

Two patients with grade IV of injury (Figure 4), one with proximal transection treated by Roux-en-Y jejunostomy drainage and the last case was 2.5 years old and had pancreatic transaction and extensive duodenal injury was treated with Whipple procedure. All four patients made a good post-operative recovery. Median hospital stay was 20 days (with range of 7-68 days), Follow-up at the outpatient clinic was asymptomatic to all children with median follow up time 45 days, and there was no mortality. Table 2 describes patient's characteristics, the severity of injuries and treatment received to all cases.

\section{Discussion}

Injury to the pancreas in children after blunt abdominal trauma is uncommon [1,2]. Moreover, the main pancreatic ductal injury is rare. But according to Arkovitz et al. pancreatic trauma occurs in up to $10 \%$ of all cases of blunt pediatric trauma and is the most common cause of acute pancreatitis in children $[7,8]$.

Pancreatic injury typically results from severe anterior- posterior

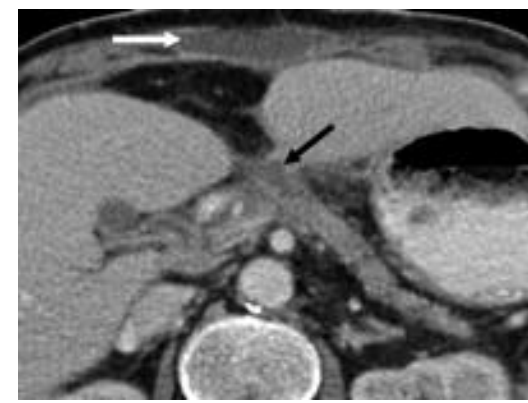

Figure 1: Grade I pancreatic injury in a patient who experienced blunt abdominal trauma. Axial CT image shows a minor contusion of the pancreatic body (black arrow). There is no pancreatic duct injury and no active bleeding. Note the hematoma of the anterior abdominal wall at the site of the injury (white arrow) $[20,21]$

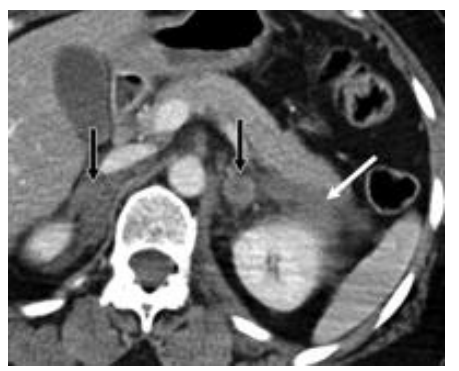

Figure 2: Grade II pancreatic injury in a patient who sustained blunt abdominal trauma. Axial CT image shows a major contusion of the pancreatic tail (white arrow). The pancreatic tail is slightly displaced interiorly because of a peripancreatic hematoma. Both adrenal glands are thickened (black arrows), a finding suggestive of contusions $[20,21]$.

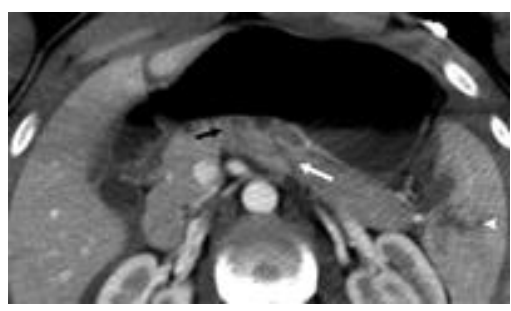

Figure 3: Grade III pancreatic injury. Axial CT image shows diffuse edema of the pancreatic parenchyma with some defined areas of contusion (black arrow). There is a transection across the pancreatic body (white arrow). A grade II splenic laceration $[20,21]$.

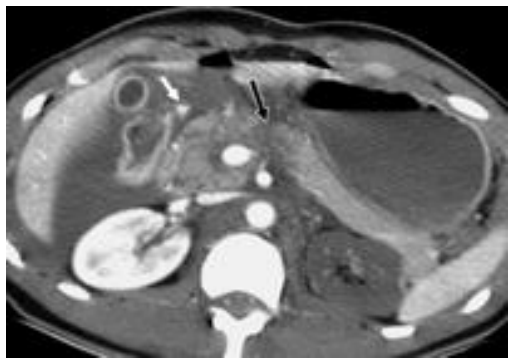

Figure 4: Grade IV pancreatic injury. Axial CT image shows a proximal pancreatic transection (black arrow) with a large peripancreatic hematoma There is also active bleeding (white arrow). The left kidney demonstrates no enhancement because of an occlusion of the renal artery (grade IV) $[20,21]$. 


\begin{tabular}{|c|c|c|c|c|c|c|c|}
\hline Case No. & Age & Sex & Mechanism of injury & Grade & S.Amylase level & Treatment & Follow up \\
\hline 1 & 2.5 & M & Fall of hard object on epigastrium. & V & Raised & Whipple Procedure & 70 days No complication \\
\hline 2 & 3.5 & $\mathrm{~F}$ & Fall from height. & 1 & Raised & Conservative & 30 days No complication \\
\hline 3 & 4 & $\mathrm{~F}$ & Fall from height. & II & Not Raised & Conservative & 30 days No complication \\
\hline 4 & 5 & M & Impact of handlebars of bicycle & 1 & Not measured & Conservative & N/A \\
\hline 5 & 5 & $\mathrm{~F}$ & Impact of handlebars of bicycle & 1 & Not Raised & Conservative & $\mathrm{N} / \mathrm{A}$ \\
\hline 6 & 5.5 & M & Impact of handlebars of bicycle & III & Raised & $\begin{array}{l}\text { Spleen-Sparing Distal } \\
\text { Pancreatectomy }\end{array}$ & 45 days No complication \\
\hline 7 & 6 & M & Impact of handlebars of bicycle & IV & Not Measured & Rounx-en-Y Jejunostomy & 60 days No complication \\
\hline 8 & 6.5 & M & Impact of handlebars of bicycle & II & Not Measured & Conservative & N/A \\
\hline 9 & 9 & M & Impact of handlebars of bicycle & III & Raised & $\begin{array}{l}\text { Spleen-Sparing Distal } \\
\text { Pancreatectomy }\end{array}$ & 50 days No complication \\
\hline 10 & 10 & $\mathrm{M}$ & Impact of handlebars of bicycle & II & Not Raised & Conservative & 30 days No complication \\
\hline
\end{tabular}

Table 2: Series of patients with pancreatic injury.

force vectors compressing the pancreas against the spine. Steering wheel impact in a motor vehicle collision is a common mechanism in adults, whereas bicycle handlebar impact is a common cause of injury for children [8], which was the commonest cause in our series (70\%). Blunt pancreatic injury is more common in children because they have a thinner or absent mantle of prospective fat which surrounds the pancreas in older adults [9].

Signs and symptoms can be minimal and difficult to elicit in this type of injury, therefore late presentation and/or diagnosis is usually common. Approximately $90 \%$ of patients with pancreatic trauma will have one or more associated intra-abdominal injuries [3].

Serum amylase level is often normal and maybe elevated due to other intra-abdominal injuries in the trauma patient [10]. Presence or absence of raised serum amylase cannot confirm or exclude the diagnosis of pancreatic injury but when elevated in diagnosed pancreatic injury it can be correlated with the severity of the injury as shown in our series. Also measurement of serial serum amylase can be used to monitor the development and resolution of pseudo cysts [11]. CT scanning is the best option for diagnosis of pancreatic injuries, especially for multiple injured children $[12,13]$.

ERCP has been used to identify the main pancreatic ductal anatomy after pancreatic trauma according to Hall et al. [14] and Rescorla et al. [15] that ERCP is an essential part of the management of children with pancreatic trauma [14] moreover a recent study by Yamana et al. [16] reported that ERCP is helpful for the diagnosis of suspected cases in pancreatic injury with grade III [16] however, in our series shown that acceptable outcome can be obtained without performing ERCP and/or surgery in the majority of cases.

Most of patients with pancreatic injuries can be treated conservatively, with 'nil by mouth', adequate hydration and good analgesia [17]. Cases with serious injuries may require total parenteral nutrition, ERCP and surgical intervention when indicated.

Cuenca et al. [18] demonstrate that non operative management appeared to be safe and more effective in treating children with pancreatic injuries, especially for the lower grade [18].

Emergency surgery is indicated if pancreatic injury associated with other abdominal injuries or if the patient haemodynamically unstable [19]. In case of persistent pseudo cysts, drainage procedure (cystogastrostomy or cystojejunostomy) or distal pancreatectomy can be performed.

Prognosis of isolated pancreatic injury is good, with minimal mortality and morbidity. There was no record of deaths in this series and no child developed post-traumatic chronic pancreatitis or diabetes.

\section{Conclusion}

Pancreatic injuries in children are uncommon and its management still controversial, some Institutions prefers conservative management, whereas others hold on the surgical option. Level of amylase is correlated with the severity of the injury when pancreatic injury is diagnosed. The management of pancreatic injuries in children depends on the grade of injury, presence of associated injuries and Hospital expertise.

\section{References}

1. National Research Council Commission on Life Sciences Committee on Trauma Research, Institute of Medicine. Injury in America: a continuing public health problem. Washington DC: National Academy Press, 1985:19

2. Haller JA Jr, Papa P, Drugas G, Colombani P (1994) Nonoperative management of solid organ injuries in children. Is it safe? Ann Surg 219: 625-628.

3. Johnson CD (1995) Pancreatic trauma. Br J Surg 82: 1153-1154.

4. Leppäniemi A, Haapiainen R, Kiviluoto T, Lempinen M (1988) Pancreatic trauma: acute and late manifestations. Br J Surg 75: 165-167.

5. Stawicki SP, Schwab CW (2008) Pancreatic trauma: demographics, diagnosis and management. Am Surg 74: 1133-1145.

6. Moore EE, Cogbill TH, Malangoni MA, Jurkovich GJ, Champion HR, et al (1990) Organ injury scaling, II: Pancreas, duodenum, small bowel, colon, and rectum. J Trauma 30: 1427-1429.

7. Kao LS, Bulger EM, Parks DL, Byrd GF, Jurkovich GJ (2003) Predictors of morbidity after traumatic pancreatic injury. J Trauma 55: 898-905.

8. Arkovitz MS, Johnson N, Garcia VF (1997) Pancreatic trauma in children mechanisms of injury. J Trauma 42: 49-53.

9. Wong YC, Wang LJ, Fang JF, Lin BC, Ng CJ, et al. (2008) Multidetector-row computed tomography (CT) of blunt pancreatic injuries: can contrast-enhanced multiphasic CT detect pancreatic duct injuries? J Trauma 64: 666-672.

10. Lee WJ, Foo NP, Lin HJ, Huang YC, Chen KT (2011) The efficacy of four-slice helical CT in evaluating pancreatic trauma: a single institution experience. $J$ Trauma Manag Outcomes 5: 1.

11. Rickard MJ, Brohi K, Bautz PC (2005) Pancreatic and duodenal injuries: keep it simple. ANZ J Surg 75: 581-586.

12. Thomas H, Madanur M, Bartlett A, Marangoni G, Heaton N, et al. (2009) Pancreatic trauma--12-year experience from a tertiary center. Pancreas 38: 113-116.

13. Klin B, Abu-Kishk I, Jeroukhimov I, Efrati Y, Kozer E, et al. (2011) Blunt pancreatic trauma in children. Surg Today 41: 946-954.

14. Hall RI, Lavelle MI, Venables CW (1986) Use of ERCP to identify the site of traumatic injuries of the main pancreatic duct in children. Br J Surg 73: 411-412.

15. Rescorla FJ, Plumley DA, Sherman S, Scherer LR 3rd, West KW, et al. (1995) The efficacy of early ERCP in pediatric pancreatic trauma. J Pediatr Surg 30 336-340.

16. Yamana I, Kawamoto S, Kamitani T, Ishikura H, Yamashita Y (2012) Pancreatic injury in children: review of 7 cases and the pertinent literature. Hepatogastroenterology 59: 574-577. 
Citation: Ghasoup A, Sadieh O, Mansor A, Alani Q, Sawaqed J (2013) Management of Pancreatic Injuries with Blunt Abdominal Trauma in Children, Case Series. J Trauma Treat 2: 160. doi:10.4172/2167-1222.1000160

Page 4 of 4

17. Keller MS, Stafford PW, Vane DW (1997) Conservative management of pancreatic trauma in children. J Trauma 42: 1097-1100

18. Cuenca AG, Islam S (2012) Pediatric pancreatic trauma: trending toward nonoperative management? Am Surg 78: 1204-1210

19. Wang GF, Li YS, Li JS (2007) Damage control surgery for severe pancreatic trauma. Hepatobiliary Pancreat Dis Int 6: 569-571.
20. Visrutaratna P, Na-Chiangmai W (2008) Computed tomography of blunt abdominal trauma in children. Singapore Med J 49: 352-358.

21. Daly KP, Ho CP, Persson DL, Gay SB (2008) Traumatic Retroperitonea Injuries: Review of Multidetector CT Findings. Radiographics 28: 1571-1590. 